\title{
Epidemics among perceived impacts on Latvia before and during COVID-19: emerging threats versus stability
}

\section{BACKGROUND}

In the time of global challenges, perception of the ongoing change at different levels of social systems modulates individual expectations, decisions, and emotional health. A previous study in Latvia revealed that perceived threats, globalization, political power, and personal control form the latent structure of perceived impacts on the country. The present study assessed the stability of this structure, comparing a relatively favorable situation and the situation of the COVID-19 emergency in Latvia.

\section{PARTICIPANTS AND PROCEDURE}

Two successive independent samples included 254 and 171 university students in 2019 and 2020, respectively. Participants assessed the impact of 15 factors on Latvia: personal impact, parents and relatives, friends, people of Latvia, political parties and leaders, Saeima (the parliament of Latvia), the government of Latvia, the European Union, the United States, other countries, global economic crises, war and military conflicts, terrorism, epidemics, and natural disasters.

\section{RESULTS}

A series of confirmatory factor analyses established partial invariance of the model. During the COVID-19 emergency, a significant shift in the perceived impact of epidemics, natural disasters, and global economic crises combined with the relative stability of personal, meso-, and macrolevel factors.

\section{CONCLUSIONS}

This stability indicates possible resources for balancing perceived threats in the situation of successful coping with COVID-19 in Latvia in Spring 2020.

\section{KEY WORDS}

perceived impact; threats; personal control; COVID-19

ORGANIZATION - 1: University of Latvia, Riga, Latvia ·2: Daugavpils University, Daugavpils, Latvia · 3: Vidzeme University of Applied Sciences, Valmiera, Latvia

AUthors' CONTRibutions - A: Study design - B: Data collection - C: Statistical analysis - D: Data interpretation .

E: Manuscript preparation · F: Literature search · G: Funds collection

CORRESPonding AUthor - Aleksandrs Kolesovs, Ph.D., Faculty of Education, Psychology, and Art, University of Latvia, 1 Imantas 7th Line, LV-1083 Riga, Latvia, e-mail: aleksandrs.kolesovs@lu.lv

to CITE this ARTICLE - Kolesovs, A., Ruza, A., \& Silkane, V. (2021). Epidemics among perceived impacts on Latvia before and during COVID-19: emerging threats versus stability. Health Psychology Report, 9(2), 129-137.

https://doi.org/10.5114/hpr.2020.101552

RECEIVED 31.07.2020 - REVIEWED 07.10.2020 • ACCEPTED 28.10.2020 • PUBLISHED 07.12.2020 


\section{BACKGROUND}

The COVID-19 pandemic impacted global functioning, countries, and lifestyles and challenged individual health and development (e.g., Holmes et al., 2020; Tull et al., 2020). From a social systems perspective, country-level processes mediate the impact of global crises and threats on individual functioning (Fjäder, 2014; Kolesovs \& Kashirsky, 2014). The perception of these macro-processes affects individual future expectations (Boehnke et al., 1998; Holman \& Silver, 2005; Steyn et al., 2010) and channels decision-making (Heckhausen \& Buchmann, 2019; Nurmi, 2004). Perceived personal control is among factors facilitating individual adjustment to changing circumstances (Nurmi, 2004; Pinquart \& Silbereisen, 2004; Seginer, 2008; Trommsdorff, 2000). Simultaneously, personal control interacts with perceived macro and global factors that form a complex view of impacts on the country. A study in Latvia (Kolesovs \& Ruza, 2019) revealed the four-factor structure of perceived impacts, including personal control, political power, globalization, and threats. To what extent has the COVID-19 pandemic changed these views of the country? The present study tested differences in perceived impacts on Latvia under two conditions - a relatively stable situation in 2019 and the COVID-19 pandemic in 2020.

The initial model of perceived impacts (Kolesovs \& Ruza, 2019) was based on ecological systems theory (Bronfenbrenner, 1979; Bronfenbrenner \& Morris, 2006) and multiple sources of global threats topical for Latvia (Chzhen, 2016; Kolesovs \& Kashirsky, 2014; Ministry of Defense \& SKDS, 2015; Ruza et al., 2016). The model involved the level of the person in its connection to the people of Latvia, the macro level, representing political power, and two factors at the global level - the interconnectedness of countries, associated with global players (the United States and the European Union), and global threats, included war, terrorism, and economic crises.

Two considerations fostered further development of the model. First, the level of mesosystem, addressing groups of close relationships in ecological systems theory (Bronfenbrenner, 1979), was underrepresented. The analyses of worries at different ecological levels (Boehnke et al., 1998) and close relationships under the economic crisis (Stein et al., 2011) confirmed the significance of the meso level in individual adjustment to threats. The underlying mechanisms involve imparting a sense of personal control through group membership (Fritsche et al., 2008) and solidarity in the face of a global threat (Der-Karabetian et al., 2014). The relatively close association of personal control with the perceived impact of people of Latvia (Kolesovs \& Ruza, 2019) indicates that the same factor can load relationships at the meso level (Figure 1).

Second, the topical political crisis in Europe and experienced consequences of the global economic crisis (Chzhen, 2016; Kolesovs \& Kashirsky, 2014; Postelnicescu, 2016) limited the scope of global problems in the initial model. In 2019, we extended the view of threatening impacts by adding natural disasters and epidemics as unpredictable and powerful changes (Fung \& Carstensen, 2006; Holmes et al., 2020; Kasapoğlu et al., 2009). The association of epidemics with socioeconomic concerns (e.g., Cerami et al., 2020) raised the prospect of their joining into a common factor.

The beginning of the pandemic and the COVID-19 emergency in Latvia (March 2020 - June 2020) raised the question regarding possible transformations of perceived impacts under the pressure of this global threat. Based on the relatively high sensitivity of people of Latvia to external impacts (Chzhen, 2016; Kolesovs \& Kashirsky, 2014; Ministry of Defense \& SKDS, 2015; Ruza et al., 2016), we expected that the level of impact of epidemics would be higher under the condition of the COVID-19 pandemic.

Another domain of possible change was the sense of personal control over the situation in the country. Control attributions form an important part of secondary control (Heckhausen et al., 2010), enhancing individual motivation and the sense of personal control in its selective mode or protecting an individual from wasting personal resources and reducing the control in the compensatory mode (Tomasik et al., 2010). Activating the sense of personal control was observed in Latvian youth during a global economic crisis (Kolesovs, 2015; Kolesovs \& Kashirsky, 2014). This change was associated with maintaining a positive view of the future under challenging conditions, as it was also found in other studies (Seginer, 2008; Tomasik et al., 2010).

As a result, we decided to test the partial invariance of the model of perceived impacts on Latvia. Our particular focus was on possible differences in the perceived impact of the epidemic threats and the sense of personal control over the situation in the country.

\section{PARTICIPANTS AND PROCEDURE}

The study started in 2019 and was not initially aimed at revealing the impact of COVID-19 pandemic threats. Focused on students' sense of belonging to Latvia, it included questions regarding perceived control and impacts on the country that provided an opportunity to explore differences in perceived impact.

\section{PARTICIPANTS}

We recruited participants in universities from Daugavpils, Riga, and Valmiera. Two successive independent convenience samples (Table 1) involved 425 university students from 18 to 49 (mean age $=25.10$ years, 


\section{Figure 1}

The model of perceived impacts on Latvia

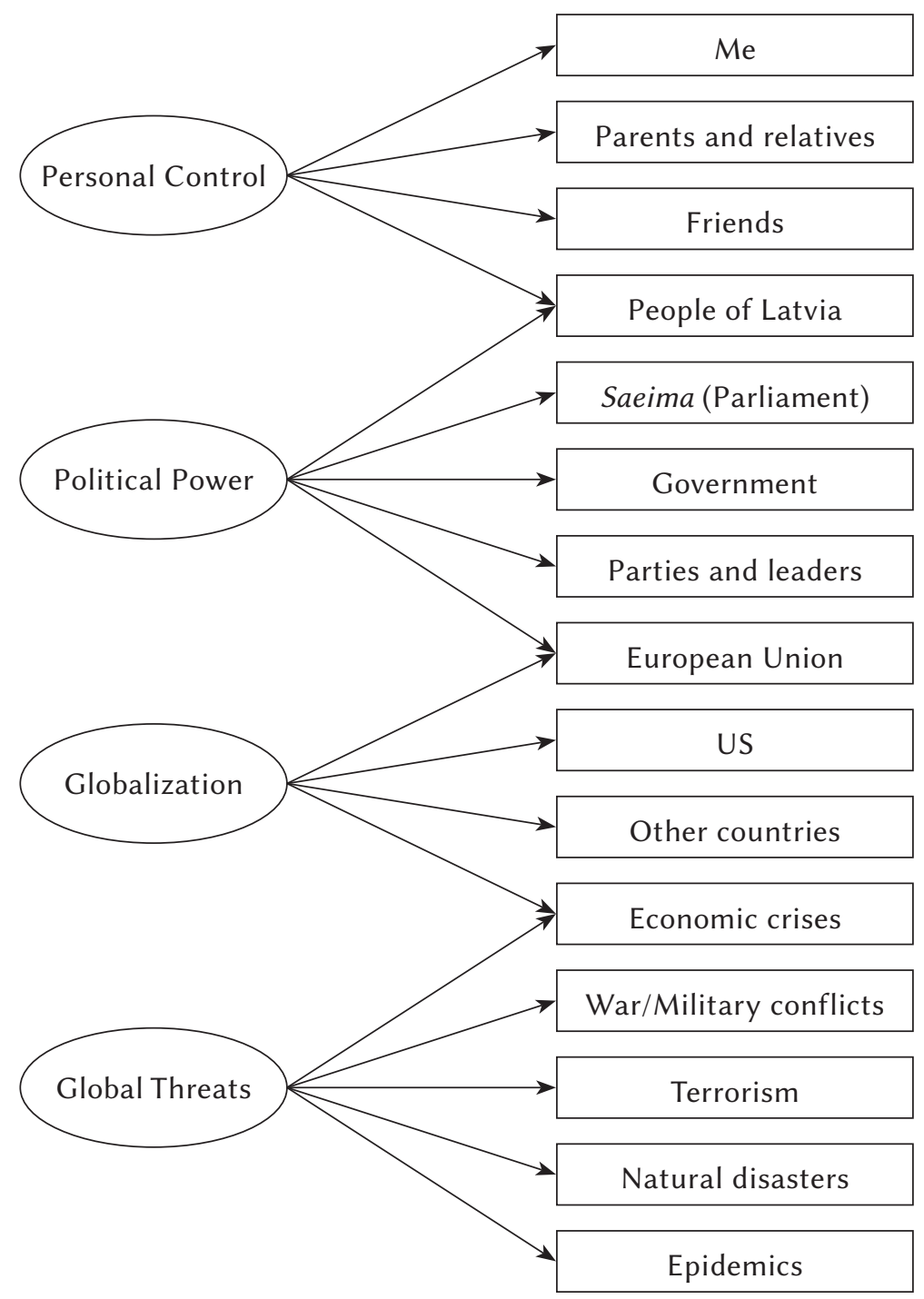

Perceived threats of epidemics before and during COVID-19

$S D=6.74,74 \%$ were female). There were no international (non-resident) students in both subsamples. The a priori sample size was calculated using an online calculator (Soper, 2020), taking into account the anticipated minimal effect size no less than .30 (Kolesovs \& Ruza, 2019), 15 indicators, four latent variables, $\alpha$ level .05, and power .80, as suggested by Westland (2010). The minimal calculated sample size was 137 for a group. Therefore, both subsamples satisfied this requirement.

The distribution of characteristics were similar in terms of gender, $\chi^{2}(1)=0.47, p=.492$, age, $t(423)=1.29, p=.199$, income, $\chi^{2}(1)=0.77, p=.380$, and marital status, $\chi^{2}(1)=0.85, p=.355$. Differences in participants' graduation were only marginally significant, $\chi^{2}(1)=0.52, p=.051$. However, students' employment rate was lower in 2020 than in 2019 , $\chi^{2}(1)=7.45, p=.006$. These differences could reflect significant socioeconomic pressure associated with the pandemic in Latvia (Rasnača, 2020).

\section{MEASURES}

The inventory contained questions regarding students' personal goals, opportunities for their fulfillment, and the sense of belonging to Latvia. However, these questions were not included in the analysis because of refocusing the topic and relatively small sample sizes in each year.

Based on the inventory applied by Kolesovs and Ruza (2019), perceived impacts on the country were assessed on a 7-point scale from 1 (no impact) to 7 (maximal impact) by answering a question: "To what extent do the factors listed below impact the future of Latvia?”. In 2019 and 2020, participants as- 


\section{Table 1}

Demographic characteristics of two successive samples of university students

\begin{tabular}{lcc}
\hline \multirow{2}{*}{ Characteristic } & \multicolumn{2}{c}{ Year } \\
\cline { 2 - 3 } & 2019 & 2020 \\
\hline Number of participants & 254 & 171 \\
Females, \% & 72 & 75 \\
Age (years), M (SD) & 24.76 & 25.61 \\
& $(6.29)$ & $(7.36)$ \\
Age (years), range & $18-48$ & $19-49$ \\
Graduated, \% & 25 & 34 \\
Employed, \% & 67 & 54 \\
Higher than median income ${ }^{\mathrm{a}}, \%$ & 60 & 56 \\
Married, \% $^{2}$ & 17 & 21 \\
\hline Note. ${ }^{\text {a } i n c o m e ~ p e r ~ p e r s o n ~(E u r o s t a t, ~ 2020) . ~}$ & &
\end{tabular}

sessed the impact of fifteen factors: you (personal impact), your parents and relatives, your friends, people of Latvia, political parties and leaders, Saeima (the parliament of Latvia), the government of Latvia, the European Union, the United States, other countries, global economic crises, war and military conflicts, terrorism, epidemics, and natural disasters.

\section{PROCEDURE}

We conducted the study in March-May 2019 and April-May 2020. In both years, sampling through an informal network of social psychologists was applied. Students were invited to participate during regular lectures in the same study courses. It ensured the successiveness of two subsamples. Their independence in the sense of between-subject design was maximized by not following any group involved in 2019 and a direct reminder to not participate in the study repeatedly. In 2020, the invitation was made online or by e-mail because of strict limitations during the COVID-19 emergency. Participation was voluntary and anonymous. After the informed consent was received, students filled in the inventory without a time limit.

We performed regular statistical tests using IBM SPSS Statistics for Windows 22.0, confirmatory factor analysis using the 'cfa' function in 'lavaan' (0.6-6) for $R$ (Rosseel, 2012), and model invariance tests with adjusted RMSEA values using 'eqMI.main' function in 'equaltestMI' (0.6.0) for $R$ (Jiang et al., 2017). Testing invariance by 'eqMI.main' focused on the metric (weak), scalar (strong), and residual (strict) equivalence of the model across groups (e.g., Putnick
\& Bornstein, 2016). Partial invariance was established through setting the most distinguished specific parameters relaxed, while other parameters were restricted. For adjusted RMSEA, the cut-off values for $.01, .05$, and .08 were applied (Yuan \& Chan, 2016). The final partially invariant model was tested for the equivalence of factor variances, covariances, and means (e.g., Cheung \& Rensvold, 2002) by 'compareFit' for nested models in 'lavaan'. Following Chen (2007), observed differences in fit indices lower than .01 were expected for invariant models.

\section{RESULTS}

We conducted a series of confirmatory factor analyses (Table 2). Model 0 tested the factorial structure presented in the introduction (Figure 1). Maximumlikelihood estimation revealed close to acceptable fit of the model (Hu \& Bentler, 1999; Kline, 2011). However, the model demonstrated metric non-invariance associated with students' gender, $\Delta \chi^{2}(14)=26.35$, $p=.023$. Taking into account the limited sample size, separate analyses for each gender group were not preferable. Therefore, we modified the model by adding two cross-loadings: Globalization on war and military conflicts and Political Power on global economic crises. As a result, Model 1 demonstrated acceptable fit and metric invariance regarding students' gender, $\Delta \chi^{2}(16)=23.39, p=.104$, and graduation, $\Delta \chi^{2}(16)=22.33, p=.133$. Adjusted RMSEA values for these tests of invariance were .085 and .082 (less than .088 as the cut-off for .05).

Simultaneously, Model 1 was not metric-invariant, $\Delta \chi^{2}(16)=41.23, p=.001$, scalar-invariant, $\Delta \chi^{2}(11)=236.05, p<.001$, and residual-invariant, $\Delta \chi^{2}(15)=142.56, p<.001$, regarding the year of the study. The following Model 2 and 3 addressed the subsample of 2019 and 2020, respectively. Model 2 demonstrated a better fit to data than Model 3. However, there was no extreme loss of fit in Model 3.

Model 4 involved a multigroup perspective on the confirmatory factor analysis. It presented the baseline for establishing partial invariance of the model in 2019 and 2020. Based on revealed metric non-invariance, the most different factorial loadings of Model 4 were relaxed in Model 5, and the model achieved partial metric invariance, $\Delta \chi^{2}(12)=20.48, p=.059$, adjusted RMSEA = .099 (less than .120 as the cut-off for .08).

Scalar non-invariance remained significant after this improvement, $\Delta \chi^{2}(11)=183.21, p=.001$. To achieve partial invariance, Model 6 relaxed the most pronounced differences in intercepts of the unconstrained Model 4 . As a result, the model achieved partial scalar invariance, $\Delta \chi^{2}(8)=4.57, p=.802$, adjusted RMSEA $=.051$ (less than .081 as the cut-off for .01)

Although Model 6 demonstrated strong partial invariance, its strict invariance - residual invariance - 
Table 2

Confirmatory factor analyses established partial invariance of the model of perceived impacts on Latvia in 2019 and 2020

\begin{tabular}{lcccccc}
\hline Model & $\chi^{2}$ & $d f$ & CFI & TLI & RMSEA & SRMR \\
\hline Model 0 (Overall) & 361.48 & 81 & .940 & .922 & .090 & .055 \\
Model 1 (Overall $\left.{ }^{\mathrm{a}}\right)$ & 301.38 & 79 & .952 & .937 & .081 & .043 \\
Model 2 $(2019, n=254)$ & 190.00 & 79 & .965 & .953 & .074 & .040 \\
Model 3 $(2020, n=171)$ & 206.86 & 79 & .929 & .905 & .097 & .070 \\
Model 4 (Configural) & 396.86 & 158 & .952 & .936 & .084 & .052 \\
Model 5 (Metric $\left.{ }^{\mathrm{b}}\right)$ & 417.33 & 170 & .950 & .938 & .083 & .055 \\
Model 6 (Scalar $\left.{ }^{\mathrm{c}}\right)$ & 421.91 & 178 & .951 & .942 & .080 & .056 \\
Model 7 (Residual $\left.{ }^{\mathrm{d}}\right)$ & 441.38 & 189 & .949 & .943 & .079 & .056 \\
Model 8 $\left(\right.$ Latent $\left.^{\mathrm{e}}\right)$ & 451.07 & 202 & .949 & .947 & .076 & .064 \\
\hline
\end{tabular}

Note. ${ }^{\text {a }}$ modified by adding cross-loadings of Globalization on war and Political Power on economic crises; ${ }^{\mathrm{b}}$ relaxed loadings of Globalization on war, Threats on epidemics, and Political Power on people and economic crises; ${ }^{\mathrm{c}}$ relaxed intercepts of epidemics, natural disasters, and economic crises; ${ }^{\mathrm{d}}$ relaxed residuals of epidemics, terrorism, friends, and personal control; ${ }^{\mathrm{e}}$ constrained latent variances, means, and covariances and relaxed covariance between Personal Control and Globalization.

remained not achieved, $\Delta \chi^{2}(15)=90.66, p<.001$. In Model 7, relaxing variances resulted in strict residual invariance of the model, $\Delta \chi^{2}(15)=19.47, p=.053$, adjusted RMSEA = .103 (less than .122 as the cut-off for .08).

Model 8 constrained latent variances, means, and covariances. Constraining latent variances did not change the model fit, $\Delta \chi^{2}(4)=2.02, p=.732$, $\triangle \mathrm{CFI}=.000, \triangle \mathrm{RMSEA}=-.001$. Constraining latent means also resulted in saving the model fit, $\Delta \chi^{2}(4)=2.03, p=.739, \Delta \mathrm{CFI}=.000, \Delta \mathrm{RMSEA}=-.001$. In turn, constrained covariances caused a marginal shift in model fit, $\Delta \chi^{2}(6)=12.49, p=.052, \Delta \mathrm{CFI}=.000$, $\triangle \mathrm{RMSEA}=.000$, and one covariance was relaxed. It improved indicators of invariance, $\Delta \chi^{2}(5)=5.64$, $p=.343, \Delta$ CFI $=.000, \Delta$ RMSEA $=-.001$. Model 8 also demonstrated an acceptable level of deviance from the less restricted Model $4, \Delta \chi^{2}(44)=54.21, p=.139$, $\Delta \mathrm{CFI}=-.002, \triangle \mathrm{RMSEA}=-.008$, and constituted the final partially invariant model regarding the year of the study (Figure 2).

Within Model 8, we assessed the significance of differences of each non-invariant parameter by constraining or relaxing it in two nested multigroup models and comparing model fit (Table 3). Most parameters significantly differed under two conditions. The difference between models in factorial loading of Globalization on war and military conflicts was marginally significant, while factorial loading of Political Power on the global economic crisis did not associate with significant differences. However, constraining any of these loadings led to the loss of partial metric invariance of Model 8.

\section{DISCUSSION}

The results demonstrated that the latent factors of perceived impacts on Latvia before and during the COVID-19 emergency were relatively stable. As expected, the assessment of partial invariance revealed a significant shift in the perceived impacts of epidemics. Under the condition of COVID-19, the impact of epidemics was perceived at a higher level (non-invariant intercept). Simultaneously, it was relatively less associated with other global threats (non-invariant factor loading) than before the pandemic, and demonstrated a broader variability of opinions regarding epidemics (non-invariant residuals) under COVID-19 emergency pressure. These findings confirm relative sensitivity of people in Latvia to topical threats, as was also observed during the economic and political tension (Chzhen, 2016; Kolesovs \& Kashirsky, 2014; Ministry of Defense \& SKDS, 2015; Ruza et al., 2016).

In parallel with epidemic threats, other natural disasters and economic issues were assessed at a higher level during the pandemic in 2020. It concurs with the view of a complex impact of the current pandemic on people and social systems at different levels, including socioeconomic effects (Cerami et al., 2020; Holmes et al., 2020; Tull et al., 2020). Simultaneously, the perceived impacts of other factors demonstrated invariant intercepts indicating relative stability regarding the year of the study. It provides evidence for perception of macro- and meso-level factors as impacting the situation in Latvia and maintaining a continuous frame of interpersonal relationships and macro-level conditions for students' socializa-
Perceived threats of epidemics before and during COVID-19 


\section{Figure 2}

Non-standardized estimates of factor loadings, intercepts (triangles), and variances for the partially invariant model of perceived impacts on Latvia. Dashed lines present added cross-loadings. Non-invariant parameters are in bold for 2019/2020. Covariance is not significant in 2020

Aleksandrs Kolesovs, Aleksejs Ruza, Vineta Silkane

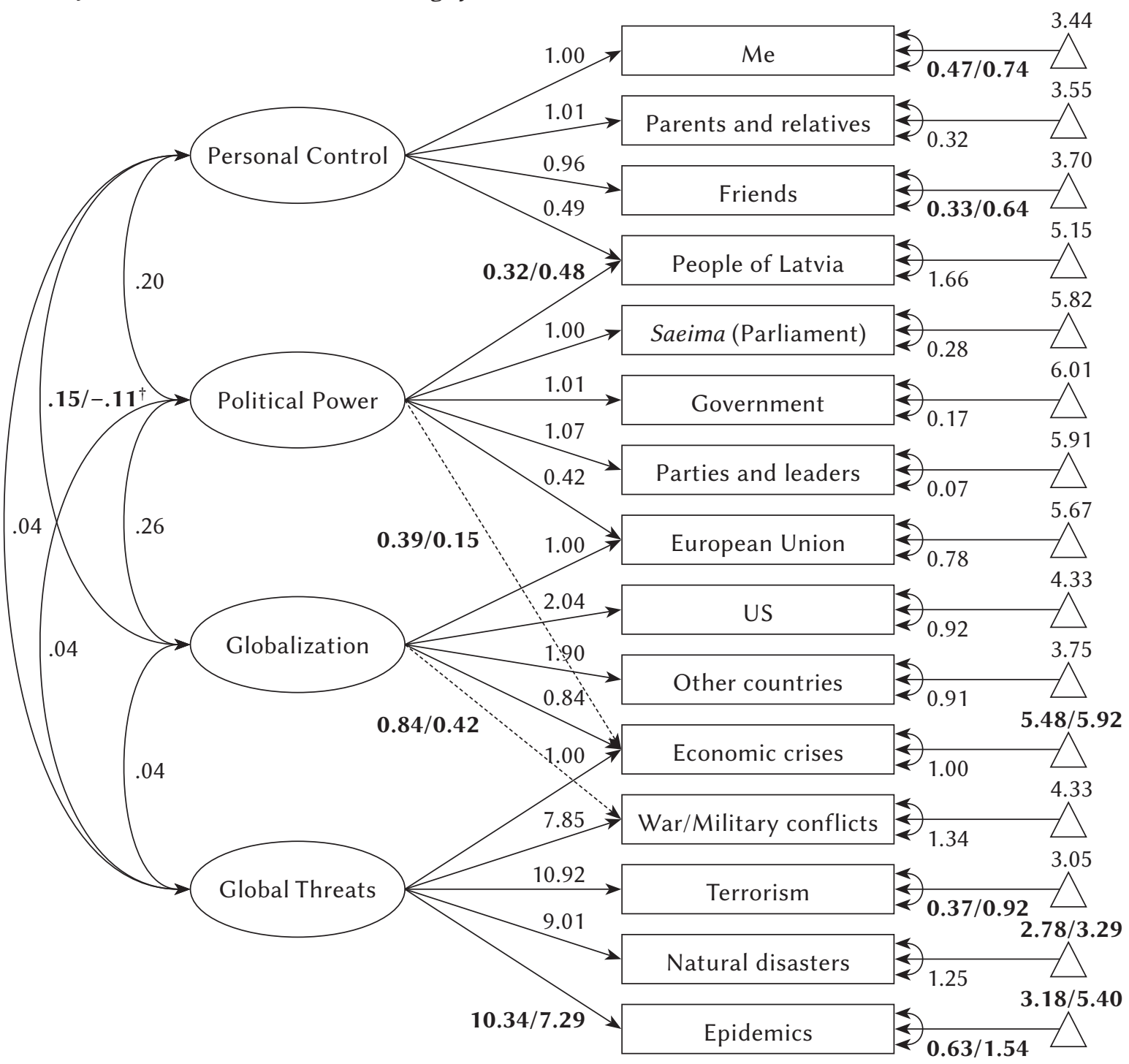

tion (Nurmi, 2004). This stability can associate with successful epidemiological coping with COVID-19 in Latvia during the emergency in Spring 2020 (European Centre for Disease Prevention and Control, 2020).

Patterns of covariance among the latent factors changed minimally and revealed only differentiation of personal impact and an impact of interconnected countries and global players in 2020. However, differences in factorial loadings addressed cross-loadings between the main factors of perceived impacts. It emphasized that global change can modulate interaction patterns at different levels of social systems. Under the condition of COVID-19, the perceived impact of political power was more closely associated with the impact of the people of Latvia. Thematically, the impact of people also appeared in students' views of the future of the country under the condition of global economic crisis (Kolesovs \& Kashirsky, 2014).

The sense of personal control joined into a factor with the perceived control of close people, forming the mesosystem. It is in line with cooperative tendencies, facilitating individual control under changing macro or global conditions (Der-Karabetian et al., 2014; Fritsche et al., 2008). The comparison of personal control in 2019 and 2020 revealed two tendencies. On the one hand, indicators of personal and shared control remained at a similar level in 2019 and 2020. Therefore, we have not found a shift in the sense of personal control during the COVID-19 emergency. It is a sign of stability in perceived personal resources, aimed at successful adjustment and adaptation in times of change (Pinquart \& Silbereisen, 2004; Trom- 
msdorff, 2000), and a personality-level indicator of emotional health (Seginer, 2008). On the other hand, the higher variability of the sense of personal control and the perceived impact of friends revealed some divergence in students' opinions. This divergence may indicate enhancing the sense of personal and shared control in some people and lowering this sense in others. Therefore, control attributions, forming a part of secondary control regulatory mechanisms (Heckhausen et al., 2010), can be activated under the pressure of pandemic threats in selective or compensatory mode, strengthening the sense of personal impact or reducing it (Tomasik et al., 2010), respectively.

Revealed non-invariant links of globalization to war and political power to global economic crises were not highly significant in an isolated comparison of a multigroup model. It confirms the complexity of the system of perceived impacts, which requires further research in broader and more representative samples. At the same time, the current study satisfied the requirements for the sample size, providing a sufficient level of power for statistical conclusions. Students' gender and education were controlled at the level of metric invariance, but a possible effect of employment should be explored in depth in further studies.

Sampling constitutes a significant limitation of the study. Compared to older adults, university students can feel a higher level of personal control (e.g., Nurmi, 2004), and generalization of our findings is limited by young people actively involved in university education. The motivation of students under different conditions also can form a source of variance in perceived impacts. Anonymity limits the analysis of possible differences among responders and nonresponders, even in well-known groups of students. However, the relative stability of the model and association of observed differences with objectively changing conditions (e.g., epidemiological) indicate no radical model transformations in 2020 .

The involvement of new groups minimized the participation of the same students in 2019 and 2020. The assessment of the model in a between-subject design did not allow us to consider the internal dynamics of perceived impacts. Simultaneously, we have used an opportunity to refocus the study under the global change, while the application of a longitudinal panel study design requires anticipation of upcoming events and continuous involvement of resources under the condition of unpredictability.

We can conclude that the main differences in perceived impacts on Latvia in 2019 and 2020 associate with objective challenges of the COVID-19 pandemic. During the emergency in Spring 2020, this global threat was reflected in students' assessment of epidemics and natural disasters despite the relatively successful epidemiological coping in Latvia. Economic concerns have confirmed the complexity of the ongoing change. Simultaneously, the relatively
Table 3

Comparison of parameters associated with noninvariance regarding the year

\begin{tabular}{|c|c|c|}
\hline Parameter & $\Delta \chi^{2}$ & $p$ \\
\hline \multicolumn{3}{|l|}{ Factor loadings } \\
\hline $\begin{array}{l}\text { Globalization on war and } \\
\text { military conflicts }\end{array}$ & 3.34 & .068 \\
\hline Threats on epidemics & 11.32 & .001 \\
\hline $\begin{array}{l}\text { Political Power on the } \\
\text { people of Latvia }\end{array}$ & 8.70 & .003 \\
\hline $\begin{array}{l}\text { Political Power on global } \\
\text { economic crises }\end{array}$ & 2.17 & .141 \\
\hline \multicolumn{3}{|l|}{ Intercepts } \\
\hline Epidemics & 211.82 & $<.001$ \\
\hline Natural disasters & 16.72 & $<.001$ \\
\hline Global economic crises & 18.07 & $<.001$ \\
\hline \multicolumn{3}{|l|}{ Residuals } \\
\hline Epidemics & 24.48 & $<.001$ \\
\hline Terrorism & 10.97 & $<.001$ \\
\hline Friends & 11.74 & $<.001$ \\
\hline Personal control (Me) & 5.88 & .015 \\
\hline \multicolumn{3}{|l|}{ Latent covariances } \\
\hline $\begin{array}{l}\text { Personal control - } \\
\text { Globalization }\end{array}$ & 6.85 & .009 \\
\hline
\end{tabular}

Note. Model fit was estimated by the maximum likelihood method, and the chi-square difference test was performed at $d f=1$.

stable sense of personal control and control at the meso and macro levels indicate possible resources for balancing perceived impacts under the condition of pandemic threats.

\section{FUNDING}

This research was partly supported by the project of the University of Latvia "Individual, technologies, and quality of education" Nr. ZD2010/AZ22, Funding Nr. Y5-AZ22-ZF-N-040.

\section{REFERENCES}

Boehnke, K., Schwartz, S., Stromberg, C., \& Sagiv, L. (1998). The structure and dynamics of worry: Theory, measurement, and cross-national replications. Journal of Personality, 66, 745-782. https:// doi.org/10.1111/1467-6494.00031
Perceived threats of epidemics before and during COVID-19 
Bronfenbrenner, U. (1979). The ecology of human development: Experiments by nature and design. Harvard University Press.

Bronfenbrenner, U., \& Morris, P. A. (2006). The bioecological model of human development. In W. Damon \& R. M. Lerner (Eds.), Handbook of child psychology: Vol. 1. Theoretical models of human development (pp. 793-828). Wiley.

Cerami, C., Santi, G. C., Galandra, C., Dodich, A., Cappa, S., Vecchi, T., \& Crespi, C. (2020). Covid-19
Aleksandrs

Kolesovs,

Aleksejs Ruza,

Vineta Silkane outbreak in Italy: Are we ready for the psychosocial and the economic crisis? Baseline findings from the PsyCovid Study. Frontiers in Psychiatry, 11, 556. https://doi.org/10.3389/fpsyt.2020.00556

Chen, F. F. (2007). Sensitivity of goodness of fit indexes to lack of measurement invariance. Structural Equation Modeling, 14, 464-504. https:// doi.org/10.1080/10705510701301834

Cheung, G. W., \& Rensvold, R. B. (2002). Evaluating goodness-of-fit indexes for testing measurement invariance. Structural Equation Modeling, 9, 233-255. https://doi.org/10.1207/S15328007SEM0902_5

Chzhen, Y. (2016). Perceptions of the economic crisis in Europe: Do adults in households with children feel a greater impact? Social Indicators Research, 127, 341-360. https://doi.org/10.1007/s11205-015-0956-z

Der-Karabetian, A., Cao, Y., \& Alfaro, M. (2014). Sustainable behavior, perceived globalization impact, world-mindedness, identity, and perceived risk in college samples from the United States, China, and Taiwan. Ecopsychology, 6, 218-223. https:// doi.org/10.1089/eco.2014.0035

European Centre for Disease Prevention and Control (ECDC) (2020). Communicable disease threats report. Week 22, 24-30 May 2020. Retrieved from https://www.ecdc.europa.eu/sites/default/files/ documents/Communicable-disease-threats-report-30-may-2020.pdf

Eurostat (2020, July 8). Mean and median income by household type - EU-SILC and ECHP surveys. Retrieved from https://appsso.eurostat.ec.europa.eu/ nui/show.do?dataset=ilc_di04\&lang=en

Fjäder, C. (2014). The nation-state, national security and resilience in the age of globalisation. Resilience, 2, 114-129. https://doi.org/10.1080/2169329 3.2014.914771

Fritsche, I., Jonas, E., \& Frankhänel, T. (2008). The role of control motivation in mortality salience effects on in-group support and defense. Journal of Personality and Social Psychology, 95, 524-541. https://doi.org/10.1037/a0012666

Fung, H. H., \& Carstensen L. L. (2006). Goals change when life's fragility is primed: Lessons learned from older adults, the September 11 attacks and SARS. Social Cognition, 24, 248-278. https:// doi.org/10.1521/soco.2006.24.3.248

Heckhausen, J., \& Buchmann, M. (2019). A multidisciplinary model of life-course canalization and agency. Advances in Life Course Research, 41, article 100246. https://doi.org/10.1016/j.alcr.2018.09.002

Heckhausen, J., Wrosch, C., \& Schulz, R. (2010). A motivational theory of life-span development. Psychological Review, 117, 32-60. https://doi.org/10.1037/ a0017668

Holman, E. A., \& Silver, R. C. (2005). Future-oriented thinking and adjustment in a nationwide longitudinal study following the September 11th terrorist attacks. Motivation \& Emotion, 29, 385-410. https://doi.org/10.1007/s11031-006-9018-9

Holmes, E. A., O’Connor, R. C., Perry, V. H., Tracey, I., Wessely, S., Arseneault, L., Ballard, C., Christensen, H., Silver, R. C., Everall, I., Ford, T., John, A., Kabir, T., King, K., Madan, I., Michie, S., Przybylski, A. K., Shafran, R., Sweeney, A. ... Bullmore, E. (2020). Multidisciplinary research priorities for the COVID-19 pandemic: a call for action for mental health science. Lancet Psychiatry, 7, 547-560. https://doi.org/10.1016/S2215-0366(20)30168-1

Hu, L., \& Bentler, P. M. (1999). Cutoff criteria for fit indexes in covariance structure analysis: Conventional criteria versus new alternatives. Structural Equation Modeling, 6, 1-55. https:// doi.org/10.1080/10705519909540118

Jiang, G., Mai, Y., \& Yuan, K. H. (2017). Advances in measurement invariance and mean comparison of latent variables: Equivalence testing and a projection-based approach. Frontiers in Psychology, 8, 1823. https://doi.org/10.3389/fpsyg.2017.01823

Kasapoğlu, A., Turan, F., \& Dönmez, A. (2009). Impacts of disasters: Comparisons of several worries in Turkey. Stress and Health, 25, 63-70. https:// doi.org/10.1002/smi.1216

Kline, R. B. (2011). Principles and practice of structural equation modeling (3rd ed.). Guilford Press.

Kolesovs, A. (2015). Anticipated macro-context before and during an economic crisis: a person-oriented approach. Baltic Journal of Psychology, 2015, 16, 127-140.

Kolesovs, A., \& Kashirsky, D. V. (2014). Anticipated future of Latvia and Russia during a global economic crisis: a mixed methods perspective. Psihologija, 47, 153-167. https://doi.org/10.2298/PSI1402153K

Kolesovs, A., \& Ruza, A. (2019). Global, macro, and personal impacts on Latvia: a latent structure of perceived control. E-psychologie, 13, 13-22. https:// doi.org/10.29364/epsy.356

Ministry of Defense of the Republic of Latvia, \& SKDS (2015). Latvijas iedzívotāju viedoklis par valsts aizsardzības jautājumiem [The public opinion of the people of Latvia on defense issues]. Retrieved from http://petijumi.mk.gov.lv/sites/default/files/title file/petijumus_2015_gada_latvijas_valsts_iedzivotaju_viedoklis_par_aizsardzibas_jautajumiem.pdf Nurmi, J. E. (2004). Socialization and self-development: Channeling, selection, adjustment, and reflection. In R. M. Lerner \& L. Steinberg (Eds.), Handbook of adolescent psychology (pp. 85-124). Wiley. 
Pinquart, M., \& Silbereisen, R. K. (2004). Human development in times of social change: Theoretical considerations and research needs. International Journal of Behavioral Development, 28, 289-298. https:// doi.org/10.1080/01650250344000406

Postelnicescu, C. (2016). Europe's new identity: The refugee crisis and the rise of nationalism. Europe's Journal of Psychology, 12, 203-209. https:// doi.org/10.5964/ejop.v12i2.1191

Putnick, D. L., \& Bornstein, M. H. (2016). Measurement invariance conventions and reporting: The state of the art and future directions for psychological research. Developmental Review, 41, 71-90. https://doi.org/10.1016/j.dr.2016.06.004

Rasnača, Z. (2020). COVID-19 and labour law: Latvia. Italian Labour Law e-Journal, 13. https:// doi.org/10.6092/issn.1561-8048/10958

Rosseel, Y. (2012). lavaan: An R package for structural equation modeling. Journal of Statistical Software, 48, 1-36. https://doi.org/10.18637/jss.v048.i02

Ruza, A., Ruza, I., Rascevskis, V., Vorobjovs, A., \& Murasovs, V. (2016). Safety and security in the EU: Perception of Latvian residents. Journal of Security and Sustainability Issues, 5, 365-375. https:// doi.org/10.9770/jssi.2016.5.3(5)

Seginer, R. (2008). Future orientation in times of threat and challenge: How resilient adolescents construct their future. International Journal of Behavioral Development, 32, 278-282. https:// doi.org/10.1177/0165025408090970

Soper, D. S. (2020). A-priori sample size calculator for structural equation models [Software]. Retrieved from http://www.danielsoper.com/statcalc/calculator.aspx?id=89

Stein, C. H., Abraham, K. M., Bonar, E. E., Leith, J. E., Kraus, S. W., Hamill, A. C., Gumber, S., Hoffmann, E., \& Fogo, W. R. (2011). Family ties in tough times: How young adults and their parents view the U.S. economic crisis. Journal of Family Psychology, 25, 449-454. https://doi.org/10.1037/a0023697

Steyn, M., Badenhorst, J., \& Kamper, G. (2010). Our voice counts: Adolescents' view on their future in South Africa. South African Journal of Education, 30, 169-188. https://doi.org/10.15700/saje.v30n2a337

Tomasik, M. J., Silbereisen, R. K., \& Heckhausen, J. (2010). Is it adaptive to disengage from demands of social change? Adjustment to developmental barriers in opportunity-deprived regions. Motivation and Emotion, 34, 384-398. https:// doi.org/10.1007/s11031-010-9177-6

Trommsdorff, G. (2000). Effects of social change on individual development: The role of social and personal factors and the timing of events. In L. J. Crockett \& R. K. Silbereisen (Eds.), Negotiating adolescence in times of social change (pp. 58-68). Cambridge University Press.

Tull, M. T., Edmonds, K. A., Scamaldo, K. M., Richmond, J. R., Rose, J. P., \& Gratz, K. L. (2020). Psycho- logical outcomes associated with stay-at-home orders and the perceived impact of COVID-19 on daily life. Psychiatry Research, 289, 113098. https:// doi.org/10.1016/j.psychres.2020.113098

Westland, J. C. (2010). Lower bounds on sample size in structural equation modeling. Electronic Commerce Research and Applications, 9, 476-487. https:// doi.org/10.1016/j.elerap.2010.07.003

Yuan, K. H., \& Chan, W. (2016). Measurement invariance via multigroup SEM: Issues and solutions with chi-square-difference tests. Psychological Methods, 21, 405-426. https://doi.org/10.1037/met0000080
Perceived threats of epidemics before and during COVID-19 